Check for updates

London, UK

Cite this as: BMJ 2021;372:n846 http://dx.doi.org/10.1136/bmi.n846 Published: 30 March 2021

\title{
Asthma attacks seen in primary care halved in England during pandemic, study finds
}

\section{Shaun Griffin}

GPs in England saw patient consultations for asthma exacerbations halve during the UK's first lockdown, a study has found, ${ }^{1}$ although the number of people needing hospital treatment remained the same.

Researchers used the Optimum Patient Care database, which collates medical records from general practices from around the UK, to study exacerbations among over 100 ooo patients in England who had at least one such event from January 2016 to August 2020. During that time there were 278996 exacerbations, most of which $(229058 ; 82 \%)$ were managed in primary care.

The researchers compared the exacerbation rate in two distinct periods of the five years studied-weeks 1 to 12 and weeks 13 to 32, which in 2020 was after lockdown was imposed on 23 March. They found that from March to August 2020 there was a significant reduction in asthma exacerbations among patients treated solely in general practice when compared with the previous four years $(-0.244$ episodes per person per year; $\mathrm{P}=0.000)$. But no significant difference was seen in exacerbations that needed a hospital visit or admission.

The lower rate of GP consultations was seen in all age groups but especially in children aged 5 to 10 and in most regions of England, except for London and the north east, the researchers reported in Thorax.

\section{Self-management}

Syed Shah, study author from the Asthma UK funded Usher Institute at the University of Edinburgh, told The BMJ that from March to August 2020 there were just 23 exacerbations per 100 patients attending primary care-half the rate seen during the equivalent period in the previous four years, when the figure was 46 exacerbations per 100 patients.

Speaking about the reduction in asthma attacks, Shah said, "It's not clear whether this was an actual improvement in asthma because of reduced pollution and [fewer] opportunities for respiratory viruses to spread or whether patients were afraid of consulting primary care and stayed home. Further research will help explain the reasons behind our findings."

Improved self-management of asthma driven by concerns about the pandemic and shielding by high risk patients may also have been factors, said the authors.

Samantha Walker, a director at the charity Asthma UK, said, "Many of our supporters have told us they were afraid to seek help during the pandemic. We cannot assume that because GPs are seeing fewer patients with asthma attacks people aren't experiencing them, as our research shows that $66.7 \%$ of people with asthma who had an attack dealt with it at home.

"We urge anyone worried about their asthma symptoms or who has had an asthma attack to speak to their GP and get help at an early stage. It is also vital that the NHS ensures everyone with asthma can get an appointment when they need it."

Thomas Beaney, a London GP who wrote a recent paper on managing asthma during the pandemic, ${ }^{2}$ said, "This finding will chime with what many of us experienced in general practice in the first wave of the pandemic. Many questions remain, however. We need further research to establish how much of this reduction is from real falls in incidence, changes to patients' care seeking behaviours, or barriers to accessing care, and whether any inequities in accessing care may have arisen.”

Aziz Sheikh, study coauthor and director of the Usher Institute, said, "We now need to replicate this work in other UK nations, progress understanding of the mechanisms underpinning these reductions, and identify what the implications are for asthma care in a post-covid world."

The study was funded by Breathe-the Health Data Research Hub for Respiratory Health, as well as the National Institute for Health Research Imperial Biomedical Research Centre and the University of Edinburgh's chancellor's fellowship scheme.

Shah SA, Quint JK, Nwaru BI, Sheikh A. Impact of covid-19 national lockdown on asthma exacerbations: interrupted time-series analysis of English primary care data. Thorax2021. doi: 10.1136/thoraxjnl-2020-216512.

2 Beaney T, Salman D, Samee T, Mak V. Assessment and management of adults with asthma during the covid-19 pandemic. BMJ2020;369:m2092. doi: 10.1136/bmj.m2092. pmid: 32513811

This article is made freely available for use in accordance with BMJ's website terms and conditions for the duration of the covid-19 pandemic or until otherwise determined by BMJ. You may use, download and print the article for any lawful, non-commercial purpose (including text and data mining) provided that all copyright notices and trade marks are retained. 